\title{
In-situ TEM Investigation of Reduction-Oxidation Reactions during Densification of Iron Oxide Nanoparticles
}

\author{
Cecile S. Bonifacio ${ }^{1}$, Gautom K. Das ${ }^{2}$, Ian M. Kennedy ${ }^{2}$, and Klaus van Benthem ${ }^{1}$
}

1. Department of Chemical Engineering and Materials Science, University of California, Davis, 1 Shields Ave., Davis. CA, 95616

2. Department of Mechanical and Aerospace Engineering, University of California, Davis, 1 Shields Ave., Davis. CA, 95616

Sintering describes the consolidation of individual (nano) particles to form a dense microstructure through the application of heat, pressure, electric fields, etc. [1] Electric field-assisted sintering (EFAS) is a type of sintering technique with a large number of studies reported in the literature and wide application. In fact, sintering studies of various oxide materials at low temperatures has been done however not much have been devoted on consolidation of iron oxide [2]. In both cases, the atomic scale consolidation mechanisms under heating rates and electrical fields during EFAS remain mostly unclear [3].

Iron oxide $\left(\gamma-\mathrm{Fe}_{2} \mathrm{O}_{3}\right)$ nanoparticles with size ranging from 5 to $50 \mathrm{~nm}$ in diameters were synthesized using a modified H2/air diffusion flame configuration [4]. Nanochains of the particles were produced by the applied magnetic field acting perpendicular to the flame direction. These particles were collected $55 \mathrm{~mm}$ above the visible flame by rapidly inserting the Aduro MEMS heating device. JEOL JEM 2500SE transmission electron microscope (TEM) and an aberration corrected JEOL JEM 2100F/C scanning transmission electron microscope (STEM) with a Gatan Tridiem parallel electron energy loss spectrometer operated at $200 \mathrm{KV}$ were used for the in situ heating studies. With a Protochips Aduro heating holder, temperatures from $200^{\circ} \mathrm{C}$ to $900^{\circ} \mathrm{C}$ with $50^{\circ} \mathrm{C}$ increments for $200 \mathrm{~s}$ were applied. TEM/STEM images and video signals were acquired while electron energy loss spectra (EELS) were recorded in between each heating cycle. The oxidation state of iron oxide particles during annealing was quantified by calculating the $\mathrm{Fe}_{3} / \mathrm{L}_{2}$ intensity ratio using the quantification method by Jacinski et al. [5].

Figure 1 shows the high angle annular darkfield (HAADF) images of the iron oxide nanochains at $400^{\circ} \mathrm{C}$ (Figure 1a) and $500{ }^{\circ} \mathrm{C}$ (Figure 1b), respectively. Neck formation between the particles and subsequent growth was observed (see Figure 1b). Further application of temperature led to rapid consolidation of the nanochains at $900^{\circ} \mathrm{C}$ [6]. EELS measurements and quantification of the $\mathrm{Fe} \mathrm{L}_{2,3}$ ionization edges (Figure 2) revealed a phase transition from $\gamma-\mathrm{Fe}_{2} \mathrm{O}_{3}, \mathrm{Fe}_{3} \mathrm{O}_{4}, \mathrm{FeO}$ and finally to $\mathrm{Fe}$ which was attributed to oxidation-reduction reactions during annealing [6]. In fact, the shift in $\mathrm{Fe} \mathrm{L}_{3}$ from $600^{\circ} \mathrm{C}-900^{\circ} \mathrm{C}$ (oxide to metal in Figure 2) of $1.4 \mathrm{eV}$ correlated to FeO-Fe chemical shift of EELS Fe $\mathrm{L}_{3}$ edge by Leapman et al. [7]. In this case, the iron oxide reduction from $\mathrm{Fe}_{2} \mathrm{O}_{3}$ to $\mathrm{Fe}$ was driven by the increasing annealing temperature resulting to increased surface diffusion for sintering starting from 400 ${ }^{\circ} \mathrm{C}$. Thus, a preferred phase of $\mathrm{Fe}_{3} \mathrm{O}_{4}$ for sintering during the in situ study was identified. The results from this study provided evidence for reduction-oxidation reaction mechanisms during sintering. Furthermore, the in situ heating experiment provided valuable information on sintering of fully oxidized nanometric material such as iron oxide [8].

[1] S.L. Kang, Sintering: densification, grain growth, and microstructure (2005)

[2] P. Saravanan, J.-H. Hsu, D. Sivaprahasam, S.V. Kamat, Journal of Magnetism and Magnetic Materials, 346 (2013) 175-177

[3] W. Chen, U. Anselmi-Tamburini, J.E. Garay, J.R. Groza, Z.A. Munir; Materials Science and Engineering A, 394, (2005)

[4] B. Guo, I.M. Kennedy, Aerosol Science and Technology, 41 (2007), 944 
[5] J. Jasinski, K.E. Pinkerton, I.M. Kennedy, and V.J. Leppert, Microscopy and Microanalysis, 12 (2006), 424

[6] C.S. Bonifacio, G. Das, I.M. Kennedy and K. van Benthem, Manuscript in preparation

[7] R.D. Leapman, L.A. Grunes, and P.L. Fejes. Physical Review B, 26 (1982), 614

[8] This work was financially supported by the University of California Laboratory Fee Program under grant \#12-LR-238313.
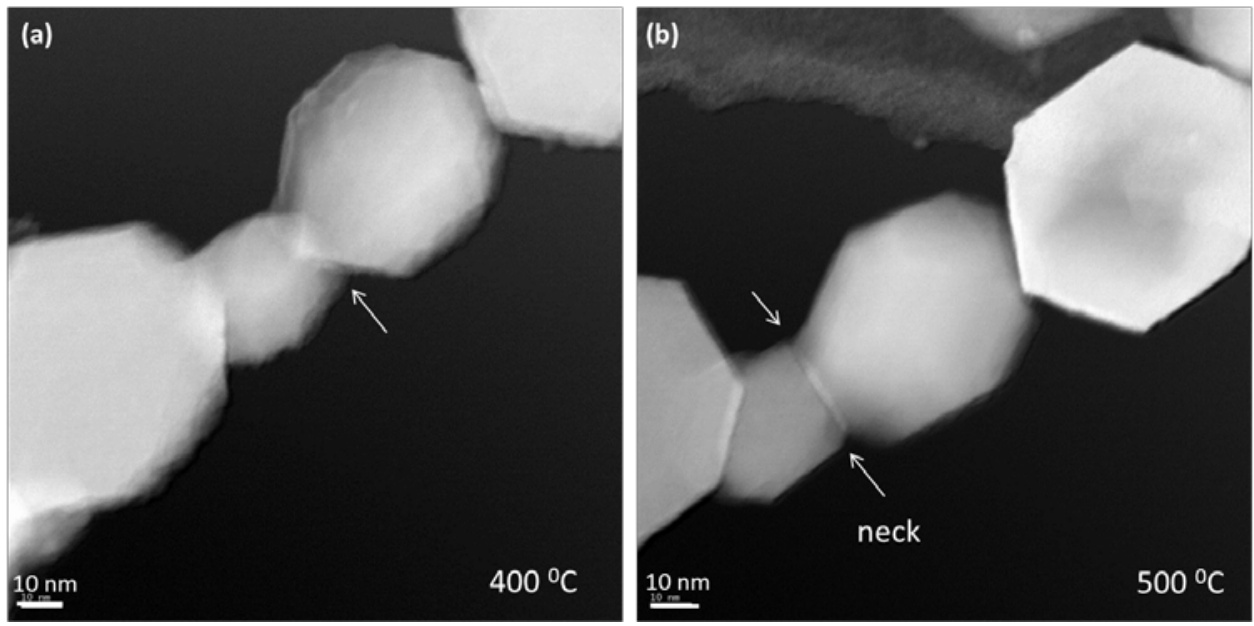

Figure 1. HAADF images of the iron oxide nanochains at $400^{\circ} \mathrm{C}\left(\right.$ a) and $500^{\circ} \mathrm{C}(\mathbf{b})$ showing neck formation between the contact areas of the marked particle.

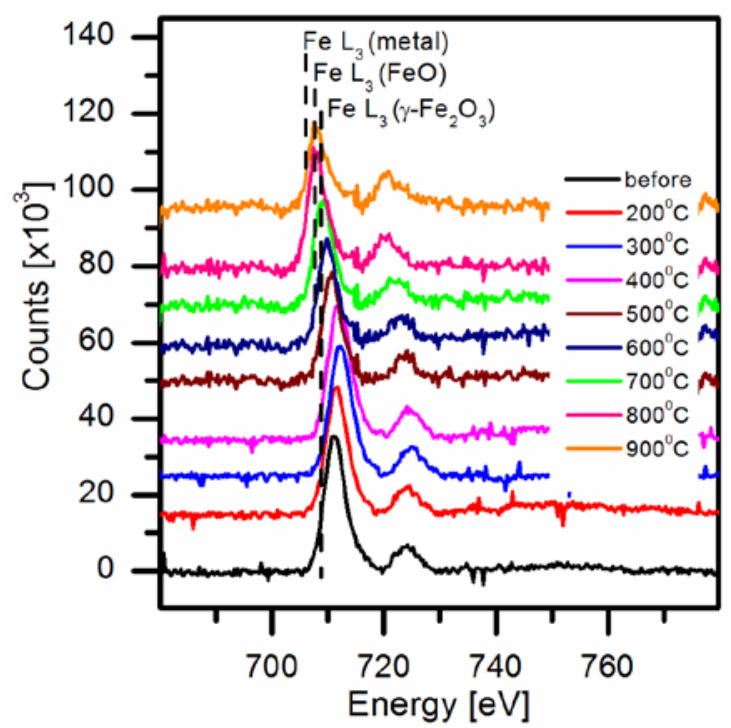

Figure 2. EELS Fe $\mathrm{L}_{2,3}$ ionization edge across the iron oxide nanoparticles acquired during each annealing temperature from the in situ heating experiment. 